\title{
الآثار الاقتصادية لظاهرة غسيل الأموال
}

\author{
مخلف عبد الله مخلف العنزي
}

باحث أكاديمي 
تعد ظاهرة غسيل الأموال من الظواهر الحديثة نسبيًا، فقد أخذت هذه

الظاهرة تنتشر بثكل كبير منذ نهاية عقد الثمانينات في القرن الماضي،

لتصبح اليوم من أهم النشاطات الاقتصادية الإجرامية التي تحقق أرباحا عالية، ورغم ذلك إلا انه لا يوجد اتفاق عام بين الدول حول مفهوم هذه الظاهرة بالضبط، وأصبح انتشار هذه الظاهرة يؤرق العديد من دول العالم، لما لها من آثار سلبية تتعكس على أداء المؤسسات والأفراد واقتصاديات مختلف الدول بشكل عام.

الكلمات المفتاحية: الأثار الاقتصادية، غسيل الأموال. نشاط اقتصادي.

\section{Abstract;}

The phenomenon of money laundering is a relatively recent phenomenon, as this phenomenon has spread significantly since the end of the eighties of the last century, and today it has become one of the most important criminal economic activities that achieve high 
profits, and despite that, there is no general agreement between countries on the concept of this phenomenon Exactly, and the spread of this phenomenon has become alarming to many countries of the world, because of its negative effects that are reflected on the performance of institutions, individuals and the economies of various countries in general.

$$
\text { الكقدمة: الكمات الدالة: غسيل الأموال, الآثار الاقتصادية, المؤسسات. }
$$

تعد ظاهرة غسيل الأموال من أهم الظواهر العالمية والتي ترافق ظهورها مع ظاهرتين عالميتين هما التطور العلمي والتكنولوجي، وكذا العولمة الاقتصادية والتي ترتب عليها عولمة الأنظمة والتنوات الدصرفية، وقد كان لهاتين الظاهرتين آثار ايجابية كبيرة، لكن بالمقابل صاحبت ظاهرة العولمة المالية الكثير من المظاهر السلبية، حيث تزايدت الظواهر الإجرامية، كتجارة المخدرات واتساع رقعة الجريمة المنظمة وكذا تزايدت عمليات السطو والاحتيال وتجارة الأسلحة والبشر وغيرها، والتي تدر دخلاً هائلاً لممارسي هذه الجرائم. 
وقد بدأت ظاهرة غسيل الأموال تنتشر بشكل كبير في كل المجتمعات بدون استثاء، وهي تهدف بالدرجة الأولى إلى تتظيف الأموال المشبوهة التي تكتسب بطرق غير مشروعة، وقد ساهت العولمة وتطور الأساليب التكنولوجية والتقنيات الحديثة المستعلة في المصارف والأسواق المالية في انتشار هذه الظاهرة التي باتت تؤرق العديد من دول العالم، لما لها من آثار سلبية تتعكس على أداء المؤسسات والأفراد واقتصاديات مختلف الدول بثكل عام.

أهمية البحث: تتبع أهمية البحث في الكثف عن تلك الآثار الاقتصادية المترتبة

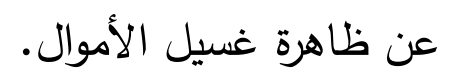

مشكلة البحث: يمكن تحديد مشكلة البحث في سؤال جوهري ورئيسي يمكن صيغته علي النحو التالي: ما هي الآثار الاقتصادية المترتبة عن ظاهرة غسيل

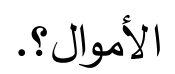

$$
\text { الههف من البحث: يكمن هدف البحث في الآتي: }
$$

1- التعرف علي ماهية غسيل الأموال قانونياً واقتصادياً, وأسباب هذه

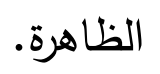

r- التعرف علي الآثار الاقتصادية لغسيل الأموال. 
وفي هذا السياق يشير الباحث في هذا البحث إلي الآثار الاقتصـادية لظاهرة غسيل الأموال, من خلال النقاط التالية:أولاً: تعريف ظاهرة غسيل الأموال. ثانياً: أسباب عمليات غسيل الأموال. ثالثا: الآثار الاقتصادية لعمليات غسيل الأموال. أولاً: تعريف ظاهرة غسيل الأموال. أصبحت ظاهرة غسيل الأموال مشكلة تؤرق العديد من الدول لما لها من آثار سلبية خطيرة تتعكس على الأفراد والمؤسسات واقتصاديات الدول بشكل عام، فقد تعددت التعريفات لعملية غسيل الأموال من الناحية القانونية والاقتصادية علي

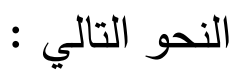

\section{1 - تعريف ظاهرة غسيل الأموال من الناحية القانونية :}

- تعرف علي أنه المحاولة بوسائل متعددة قد تكون بعضها من رجال الاعمال بهدف إخفاء وغسيل الاموال وأيضاً مصدر الكسب غير المشروع للأموال حتى 
يمكن إعادة استثمارها دون خوف من امكانية مصادرتها وذلك بوضعها في قنوات

$$
\text { مالية أو اقتصادية مشروعة('). }
$$

- كما عرف (Hasmet Sarigul) غسيل الأموال بأنه "العملية التي يتم من خلالها عائدات الجريمة, والملكية الحقيقية لتلك العائدات تكون مخفية أو مبهمة بحيث تكون العائدات يبدو أنها تأتي من مصدر شرعي"(؟). - ويري "باسلي روبرت" غسيل الأموال " أنها عملية اكتساب أموال بطريقة غير شرعية، وهي تشمل أموال الأنشطة الإجرامية والتي ترتبط عادة بتجارة المخدرات والجريمة المنظمة وأنشطة السوق الموازي وغيرها من الجرائم، وتحويلها بعد ذلك إلى أموال ذات مصادر مشروعة"(־).

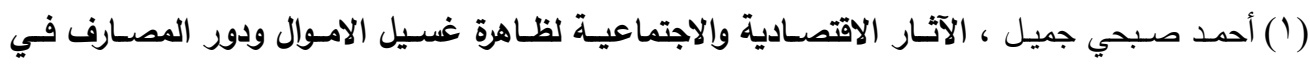

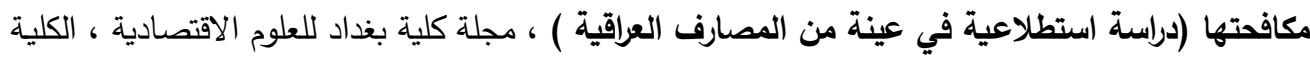

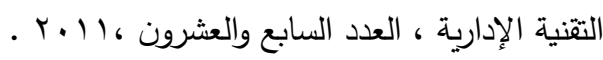

(2) Hasmet Sarigul; MONEY LAUNDERING AND ABUSE OF THE FINANCIAL SYSTEM, International Journal of Business and Management Studies, 2013, P. 288.

(3) Pasley, Robert, S (Editor).; "Study Guide for the CAMS Certification Examination", Fifth Edition, the Association of Certified Anti-Money Laundering Specialists (ACAMS), Miami, USA, 2002, P.156. 
- وفي ذات السياق عرف" السميرات " غسيل الأموال بأنه عملية إخفاء أو تمويه المصادر ووسائل الحصول غير المشروعة للأموال المنقولة وغير المنقولة المتأتية من ارتكاب الجرائم المنظمة (تجارة المخدرات، اختلاس المال العام، الفساد...وغيرها)، ومن ثم العمل على إدخال هذه الأموال في نطاق الدورة الاقتصادية وصولاً إلى استثمارها وتداولها بين الناس('). - وقد عرف قانون مكافحة غسيل الأموال المصري عملية غسيل الأموال(؟) بأنها: "كل سلوك ينطوي على اكتساب أموال أو حيازتها أو التصرف فيها أو إدارتها أو حفظها أو استبدالها أو إيداعها أو ضمانها أو استثمارها أو نقلها أو تحويلها أو التلاعب في قيمتها إذا كانت متحصله من جرائم المخدرات، أو جرائم (1) عبد محمود هلال السميرات،"عمليات غيل الأموال بين الاقتصاد الإسلامي والاقتصاد الوضعي"، مرجع

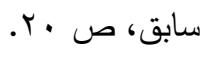
(r) وفي عام 10 • ب تم تعديل قانون مكافحة غسل الأموال ونص التعديل على حالات وصور جرائم غسيل

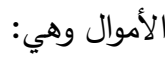

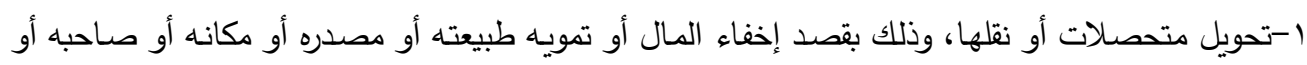

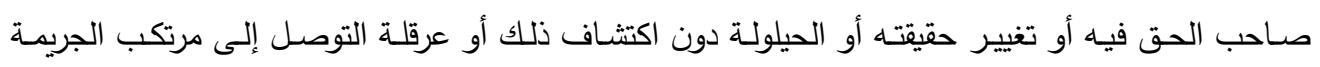

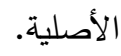

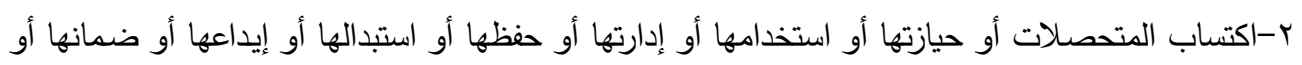

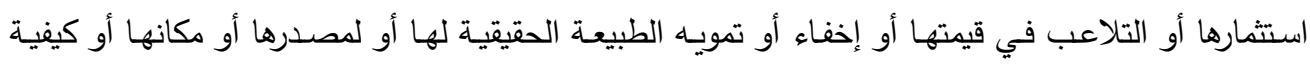
التصرف فيها أو حركتها أو ملكيتها أو الحقوق المتعلقة بها. 
الإرهاب، أو جرائم الآثار، أو جرائم الاعتداء على المال العام أو الخاص، أو جرائم الأسلحة والمفرقعات مع العلم بذلك ، متى كان القصد من هذا السلوك إخفاء المال أو مصدر تمويله أو مكانه أو صاحبه، أو تغيير حقيقته أو الحيلولة دون اكتثاف ذلك أو عرقلة التوصل إلى شخص من ارتكب الجريمة المتحصل

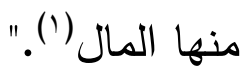

- أما المشرع الكويتي فقد عرف غسيل الأموال(؟) بأنها هي عملية أو مجموعة من عمليات ماليـة أو غير ماليـة تهدف إلى إخفاء أو تمويـه المصدر غير المشروع للأموال أو عائدات أي جريمـة وإظهارها في صورة أموال أو عائدات متحصله من مصدر مشروع ويعتبر من قبيل هذه العمليات كل فعل يساهم في

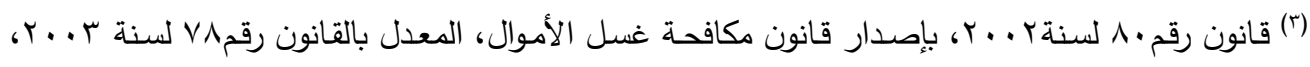
صז'.

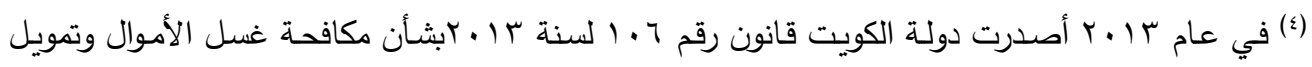

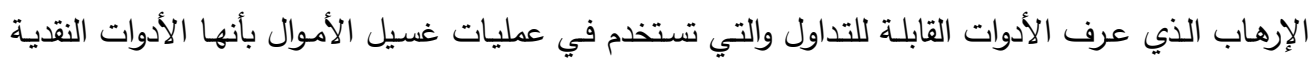

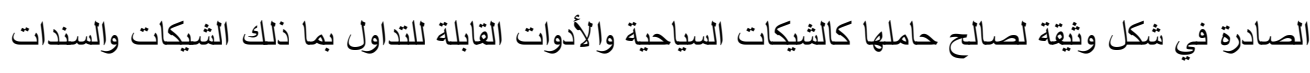

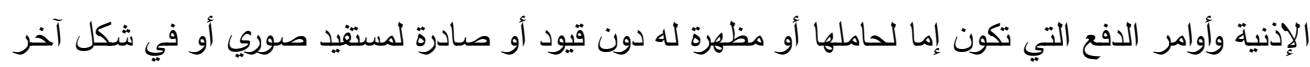

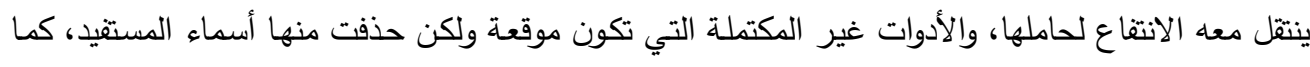

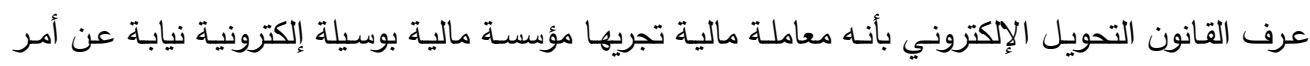

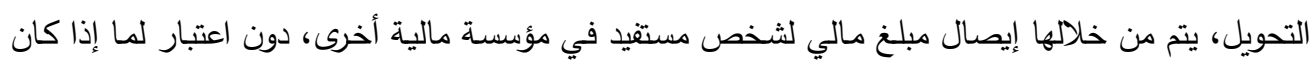

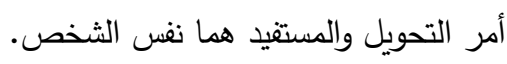


عملية توظيف أو تحويل أموال عائدات ناتجة بصورة مباشرة أو غير مباشرة عن

$$
\text { جريمة أو إخفاء أو تمويـه مصدرها ('). }
$$

r - تعريف ظاهرة غسيل الأموال من الناحية الاقتصادية :

رغم الاختلاف الظاهر بين الباحثين الاقتصاديين حول مفهوم هذه الظاهرة،

إلا أنه أطلق عليها عدة مصطلحات منها " تبيض الأموال" أو " تنظيفها" أو " تطهيرها" وهي كلها مرادفات لمصطلح غسل أو غسيل الأموال(r). وهناك الكثير من التعريفات، يمكن للباحث التعرض لأكثرها تعبيرًا عن الظاهرة, ومنها:-

- تعرف غسيل الأموال في اتفاقية الأمم المتحدة ( فيينا 9^^ ()) لمكافحة الاتجار غير المشروع في المخدرات في المادة الثالثة بأنها: الأفعال التي من شأنها تحويل الأموال أو نقلها مع العلم بأنها مستمدة من أي جريمة من جرائم المخدرات أو من فعل الاشتراك في مثل هذه الجريمة، بهدف إخفاء المصدر غير المشروع للأموال أو مساعدة أي شخص متورط في ارتكاب مثل هذه الجريمة أو الجرائم للإفلات من العواقب القانونية لأفعاله وكذلك إخفاء أو تمويه حقيقة (') قانون رقم ب لسنة r . . بفي شأن مكافحة عمليات غسيل الأموال: دولة الكويت, ص ।.

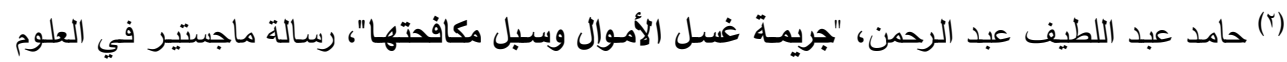

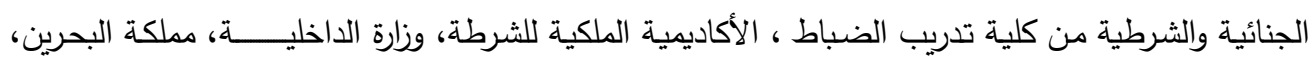

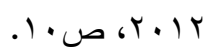


الأموال أو مصادرها أو مكانها أو طريقة التصرف فيها أو حركاتها أو الحقوق

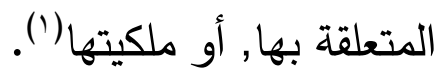

- أمـا تعريف غسيل الأموال حسب ما جاء في" اتفاقية باليرمو" وهي اتفاقية

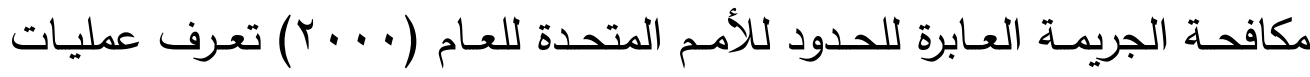
غسيل الأموال في المادة رقم(T) بأنها عبارة عن عمليات تحويل أو نقل أملاك مـع العلم بأن مصدرها نـاتج عن جريمـة جنائية وذلك بقصد حجب أو إخفاء مصدرها غير المشروع، أو مساعدة أي شخص له علاقة بارتكاب الجريمة ذات الصلة للتهرب من التبعات القانونية لأفعاله لإخفاء أو تمويـه الطبيعة الحقيقية والمصدر والموقع والتصـرف والنقل والحقوق المتعلقة بها أو ملكية الأمـلاك مـع العلم بان مصدرها جريمة جنائية وحيازة وامتلاك أو استخدام أملاكُ عرف عند وقت استلامها بأنها نتجت عن جريمة جنائية أو من المشاركة في جريمة(؟).

(5) اتفاقية الأمم المتحدة لككافحة الاتجار غير الششروع في المخدرات والمؤثرات العقلية، الأمم المتحدة ، .1101911 (1) اتفاقية الأمم المتحدة لمكافحة الجريمة المنظمة عبر الوطنية والبروتوكولات الملحقة بها، المكتب المعني

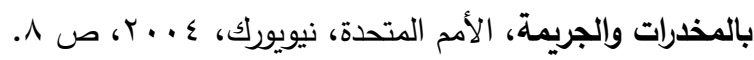


- كما عرف الاتحاد الأوربي مصطلح غيل الأموال سنة ـ99 ابأنه: "تحويل أو نقل الملكية مع العلم بمصادرها الإجرامية الخطيرة لأغراض التستر وإخفاء الأصل غير القانوني لها أو لمساعدة أي شخص يرتكب مثل هذه الأعمال('). - وفي تعريف أخر أكثر بساطة يعرف غسيل الأموال بأنه " التصرف في النقود ، بطريقة تخفي مصدرها وأصلها الحقيقي," وفي ذات السياق يعرف بأنه" تحويل العائدات غير المشروعة من نظام يقوم علي النقد الي نظام يقوم علي العمل"(؟). - هذا وقد أورد "الأخضر عزي" عدد من التعريفات ومنها: أن مفهوم غسيل الأموال عبارة عن مجموعة من العمليات المستمرة والمتلاحقة وبطريقة متعدة من أجل إدخال أموال قذرة ناتجة عن أنثطة موازية وخفية من خلال الاقتصـاد غير الرسمي إلى قنوات الاقتصاد الرسمي بغية إكسابها صفة شرعية عن طريق الوساطة المالية("). وجريمة غسيل الأموال لا تقف عند حد امتلاك شخص لمال

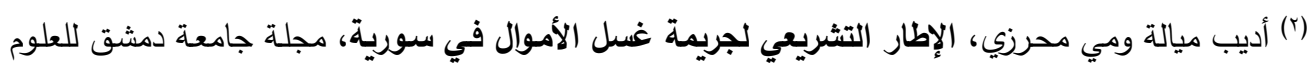

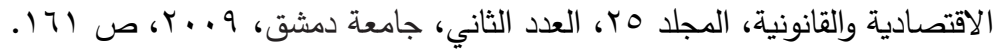
(r) حامد عبد اللطيف عبد الرحمن، جريمة غسل الأموال وسبل مكافحتها ، مرجع سابق ، ص 9. (๕) الأخضر عزي، " دراسة ظاهرة تبيضض الأموال عبر البنوك (تحليل الظاهرة في البنوك الجزائريـة) ، مجلة

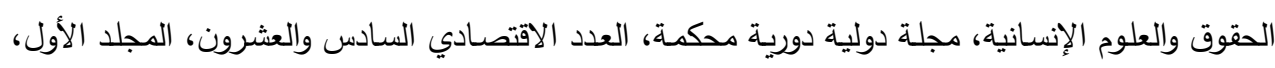

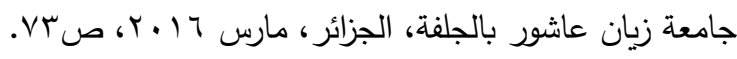


غير مشروع وإدخاله في النظام المالي للدولة، بل هذا مفهومها البسيط. وهي في الحقيقة تتعدد أنماطها وتطال المسؤولية مرتكبيها والمساهمين فيها والمتداخلين والمنتفعين، ولعل الوقوف على أنمـاط جرائم غسيل الأمـوال يستـاعي المفهوم القانوني لهذه العملية(') - (')

- تشمل عمليات غسيل الأموال " مجموعة الأنشطة التي تتم بعيداً عن أجهزة الدولة ولا تسجل في حسابات الدخل القومي وهذه الأنشطة تمثل مصدراً للأموال القذرة التي يحاول أصحابها غسلها في مرحلة تالية ، وذلك باجراء مجموعة من العمليات والتحويلات المالية والعينية علي الأموال القذرة لتغيير صفتها غير المشروعة في النظام الثرعي وإكسابها صفة الشرعية(') . نلاحظ من خلال هذه التعريفات، أنها تلتقي في عنصرين مهمين من عناصر تحليل غسيل الأموال، وهما عدم شرعية المصدر ، ومحاولة ضم تلك الأموال في

(०) تميم طاهر أحمد، المسؤولية الجنائية عن جرائم غسيل الأموال، مجلة الحقوق، كلية القانون، الجامعة

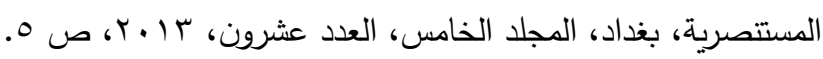

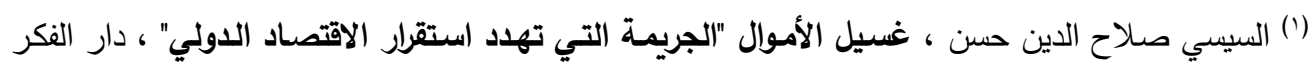

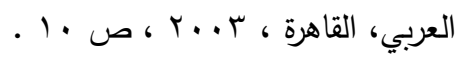


الاقتصاد الرسمي، إلا أن هذه التعريفات تتمايز أيضا من حيث موضوعها، وغايتها، أو طبيعتها حسب ما يلي (')-

- - مسب موضوعها: يمكن القول أن غسيل الأموال هو فن توظيف الوسائل المشروعة في ذاتها، سواء كانت مصرفية أو اقتصادية على العموم، لتأمين حصاد و إخفاء الأموال المتحصل عليها من إحدى الجرائم. - - من حيث غايتها: فهي تستهدف ضخ الأموال غير النظيفة (كأموال التجارة بالمخدرات وسرقة الأعمال الفنية والتحف، والاتجار بالرقيق... الخ) في"أنبوب" الأنثطة الاقتصادية والاستثمارية المشروعة، سواء على المستوى الوطني أو الدولي، على نحو يكسبها صفة المشروعية في نهاية المطاف، وهكذا تتخلص هذه الأموال من مصدرها الأصلي غير النظيف، لتتجذر بذلك من جديد وسط اقتصاد رسمي ومشروع. - - من حيث طبيعتها: لعل أهم ما يميز هذه الظاهرة أنها جريمة تبعية من ناحية، وأنها قابلة للتداول من ناحية أخرى، فهي من الناحية الأولى جريمة تبعية تفترض وقوع جريمة أصلية سابقة لها، ومن ناحية ثانية:

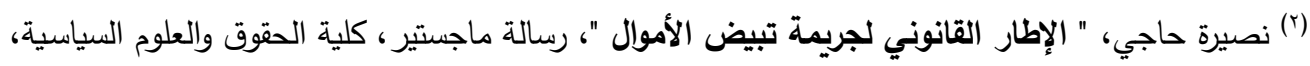

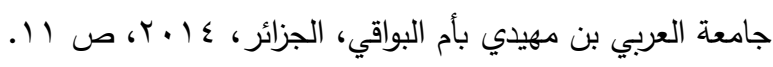


:هي جريمة قابلة للتداول إن لم تكن جريمة دولية بالفعل، فالغالب دوما هو

وقوع الجريمة الأصلية على إقليم دولة ما، بينما يتوزع نشاط غسيل الأموال

على أقاليم دول أخرى، وهكذا تتبعثر الأركان المكونة للجريمة عبر الحدود،

وهو أمر يصعب من فعالية الملاحقة القضائية، لاسيما مع ما يثيره مشكل

مجال الاختصاص ومدى الاعتراف بالأحكام القضائية الصادرة في بلد

الجريمة الأصلية.

وبناءً على ما سبق كله فإن عملية غسيل الأموال تتطلب توافر ثلاث

عناصر مهمة هي ('):

ا ـ أموال ناتجة عن أنشطة غير مشروعة، محددة وفقا للقوانين المحلية

أو الاتفاقات الدولية، ويطلق على هذه الأنشطة "الجريمة الأولية أو

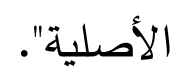

r. واقع تشريعي وسياسي وأمني، لا يسمح بالاستفادة من هذه الأموال

على حالتها تلك.

(') عطية فياض، جريمة غسيل الأموال في الفقه الإسلامي"، مرجع سابق ، صبr. 
r. أشخاص أو مؤسسات تتولى مهمة تبيض هذه الأموال من خلال أنشطة مشروعة، بهدف إخفاء مصدرها الحقيقي.

عندما تتنشر عمليات غسيل الأموال في أي دولة، فلا شك أن تتجم عنها العديد من المشكلات والآثار سواء كانت اقتصادية، اجتماعية أو سياسية، لا يقف خطرها عند الأموال التي فقدها المتمع نتيجة ممارسة الجرائم الأصلية أو التي فقدها نتيجة عدم مصادرة أموال هذه الجرائم، بل تمتد هذه الآثار إلى كافة المراحل المتتابعة التي تتم خلالها جريمة غسيل الأموال. ثانياً: أسباب عمليات غسيل الأموال. لعمليات غسيل الأموال الكثير من الأسباب و الدوافع فلا يمكن أن تأتي هذه العمليات من فراغ، بل لابد من سبب دافع للأفراد للقيام بمثل هذه العمليات، فالأسباب يمكن تقسيمها إلى أسباب مباشرة وأسباب غير مباشرة، وهي على النحو التالي (') - n (n)

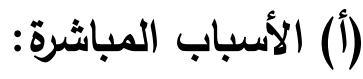
هناك الكثير من الأسباب المباشرة والتي من بينها ما يلي: (7) عبد محمود هلال السميرات، "عمليات غسيل الأموال بين الاقتصاد الإسلامي والاقتصاد الوضعي" ، مرجع

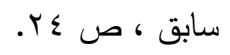




\section{ا ـ البحث عن الأمان واكتساب الشرعية خثية المطاردة القانونية:}

حيث يمثل هذا السبب دافعاً أساسياً لمرتكبي الأعمال الإجرامية، فكلما ازدادت الأموال المتولدة عن الأنشطة الإجرامية قوي الدافع لغسيلها، فمرتكب الجريمة يقوم بغسيل أمواله حتى لا يطارد قانونياً ولإبعاد الثبهة عنها.

\section{r • وجود بعض الدول التي تشجع عمليات غسيل الأموال:}

فهناك دول تشجع عمليات غسيل الأموال، خاصـة الدول النامية التي تعتمد على النقد ولديها اقتصادات غير رسمية واسعة النطاق، وتعلن صراحة أنها على استعداد لتلقي الأموال القذرة المغسولة وتقدم لها التسهيلات الممكنة، بل إنها حتى لا تفرض عليها الضرائب(') وهي الدول التي تسمى "الملاذات الضرببية" ، فعلى سبيل المثال مدينة "ناسو" عاصمة جزر البهاما، لا يزيد عدد سكانها عن 250 ألف نسمة ويوجد بها أربعة آلاف مصرف شبه متخصص في تمويل تجارة

(1) Nikos Passas; Financial intermediaries - Anti-money laundering allies in cashbased societies?, AntiCorruption Resource Centre, U4 Issue, April 2015 No 10, p.3. 
السلاح والتي تمثل 00٪ من أنشطتها، وهي تعد من أهم مراكز غسيل الأموال في العالم، كما أن هناك دول وجزر أخرى غيرها (1).

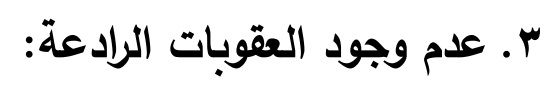

ساهم تباين التشريعات وقواعد الإثراف والرقابة بين الدول المختلفة على فتح المجال لوجود بعض الثغرات التي تستطيع أن تتفذ منها هذه الأموال القذرة، بالإضافة إلى المرونة والبطء الذي يميز المحاكمات هناك أحكام تتسم في حالة الإدانة بالتخفيف عن الجاني، إضافة إلى وجود حالات العفو وتخفيف العقوبة والإفراج عن الدجرمين في المواسم والأعياد، فلو قدرت العقوبة للمجرم الذي يقوم بغسل أمواله لكانت هذه العقوبة رادعاً للمجتمع بأسره، ولما اندفع الأفراد لارتكاب الجرائم الأصلية ومن ثمة القيام بغسيل أموالهم. (ب) الأسباب غير المباشرة: هناك الكثير من الأسباب غير المباشرة نذكر منها ما يلي:

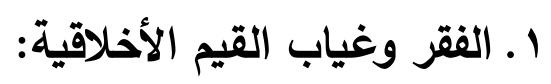

(†) الطيف عائشة، "ظاهرة غسيل الأموال وأثرها علي اقتصاديات دول العالم العببي دراسة حالة الجزائر"، كلية

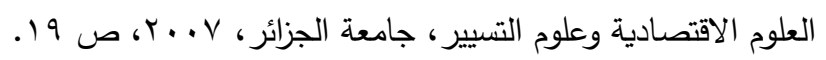


يدفع بؤس وحرمان الكثير من الفقراء والمحرومين من الناس إلى التفكير في كيفية الحصول على المال بغض النظر عن مصدره، وعند الحصول عليه بطرق غير مشروعة يفكر في كيفية إخفاء مصادر هذه الأموال وإبعاد الثبهة عنها فيلجأ إلى وضعها بالبنوك ومن ثمة إدخالها في أوجه استثمار مختلفة شرعية. فضلا عن وجود سلبيات وتشوهات في القيم الدينية والخلقية لدي بعض رجال الأعمال، في الدول الجاذبة لغسل المال الحرام، بما يسمح لهم بالقيام بعمليات الغسيل مقابل نصيب وافر منه (1).

\section{r. البطالة:}

تعتبر البطالة مرضاً اجتماعياً لما يتصل بها من فراغ، فالإنسان عندما يبقى لساعات طويلة في فراغ يأخذ بالتفكير غير السليم، فيندفع بعد ذلك إلى ارتكاب الكثير من الجرائم في سبيل الحصول على المال بأي وسيلة، ومن ثمة يندفع إلى إخفاء هذه الأموال عن المجتمع والرقابة وذلك بغسلها(؟). r. ارتفاع معدلات الضرائب والرسوم:

(1) محمد بن احمد صالح الصالح، "غسل الأموال في النظم الوضعية رؤية إسلامية" ، المؤتمر العالمي الثالث

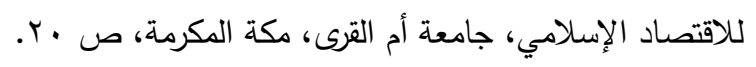
(r) عبد محمود هلال السميرات ، "عمليات غسيل الأموال بين الاقتصاد الإسلامي والاقتصاد الوضعي" ،

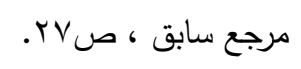


يؤدي ارتفاع معدلات الضرائب على الأنشطة الاقتصادية إلى محاولة

البعض التهرب من هذا العبء الضرببي، خاصة إذا ساد المجتمع الثعور بأن حصيلة الضرائب لا تنفق في المرافق العامة، ولا توجه إلى استخدامات سليمة، أو انه لا توجد عدالة في توزيع الدخل القومي بشكل عام، ومن هنا يبدأ الغش الضريبي أو التهرب غير المشروع من الضريبة('). ع ـ الفساد الإداري والسياسي: إذ يقوم بعض المسئولون من مختلف دول العالم باستغلال مناصبهم للحصول على عمولات وشاوى مقابل تمرير صفقات معينة أو إعطاء تراخيص حكومية أو للحصول على خدمات عامة(؟).

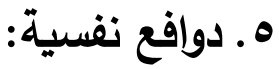

يلجأ المرو أحياناً إلى وسائل غير شرعية لتحقيق أمانيه وتطلعاته ورغباته الثخصية باستخدام بعض الوسائل التي تمكنه من الوصول إلى هدفه، لذا فالعامل النفسي يمثل دورًا بارزًا في زيادة عمليات غسيل الأموال، فيسعى الأفراد (r) الطيف عائشة ، "ظاهرة غسيل الأموال وأثرها علي اقتصاديات دول العالم العربي دراسة حالة الجزائر"، ، مرجع سابق ، ص זr.

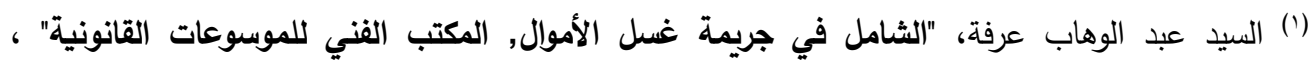

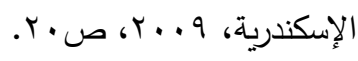


إلى اكتساب المال بطرق غير مشروعة ومن ثمة السعي نحو إخفاءه وذلك بغسله لمساواة وضعهم الاجتماعي والاقتصادي بالأغنياء في مجتمعهم ('). ثالثا: الآثار الاقتصادية لعمليات غسبل الأموال.

الواقع أن الآثار الاقتصادية أو المخاطر أو الأضرار لعمليات غسيل الأموال تصب في استتزاف الاقتصـاد الوطني للدول, حيث أن نقل الأموال إلي خـارج البلاد بقصد غسلها في بلدان أخري, يؤدي إلي حرمان البلد من الأموال والأرصدة الموجودة فيها والتي تغذي الاقتصاد الوطني, مما يحول دون استثمار تلك الأموال في مشاريع اقتصادية وتنمويسة تدر دخولاً للدولتة وللأفراد, وتسـاهم في الحد من البطالة, وتعمل علي زيادة التشغيل وارتفاع معدلات نسبة القوي العاملة, وينتج عن استنزاف الاقتصاد الوطني مشاكل اقتصادية واجتماعية وسياسية مختلفة منها زيـادة الدين الخارجي والداخلي علي عبء الدولة, وزيـادة عجز الموازنـة السنوية

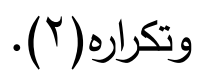

(†) عبد محمود هلال السميرات، "عمليات غسيل الأموال بين الاقتصاد الإسلامي والاقتصاد الوضعي" ، مرجع

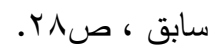

(2)World Bank Institute (2002) Christian Eigen-Zucchi with the assistance of Erin Farnand under the guidance of Daniel Kaufmann Anti-Money Laundering Literature Search Alphabetical WorldBank 
وقد توصلت احدي الدراسات في الولايات المتحدة الأمريكية إلي أن الأموال

غير المشروعة أدت إلي انخفاض الإنتاجية في الاقتصساد الأمريكي بنسبة VV بسبب نمو القطاع الاقتصـاد غير الرسمي بمعدل أسرع من معدل نمو القطاع الاقتصادي الرسي('). الأمر الذي يترتب عليه أن عمليات غسيل الأموال تقود إلي الركود الاقتصادي.

جدير بالذكر أن الآثار السلبية التي تترتب على عمليات غسيل الأموال المشبوهة من الناحية الاقتصادية تتعدد بشكل يؤثر على الاقتصـاديات المحلية ككل، ومن بين هذه الآثار ما يلي: ا ـ أثر عمليات غسيل الأموال على الاخل القومي:

Institute(http://www.worldbank.org/wbi/governance) visited on: 1/3/2020, 2.00am . p18.

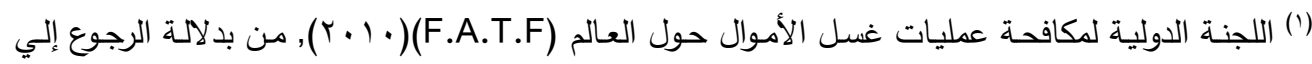

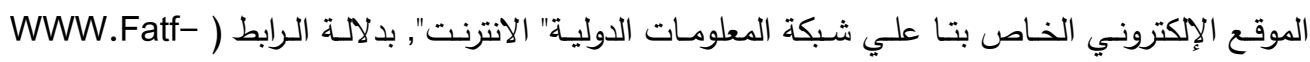
gafi.com 
تتم عمليات غسيل الأموال لأموال مقتطعة أصلا من الدخل القومي، لتتحول إلى العصابات الإجرامية ومنظماتها، ليتم تهريبها بعد ذلك خارج البلاد أو غسلها داخل الوطن، مما يترتب عليه مفاسد اقتصادية متعددة منها ('): أ. فقدان الاقتصاد للسيولة سواء من العملة المحلية أو الأجنبية التي تلتهم الاحتياطي الأجنبي الخاص بها مع كل عملية غسل دولي أو محلي يترتب عليها تحويلات نقدية إلى الخارج عبر المصارف.

ب. حرمان المجتمع من ثمرة استثمار الأموال المهربة خارج بلده، وفي أرضه ولمصلحته، مما يؤدي إلى انخفاض مستوى الإنتاجية واتجاهها التتازلي بالنسبة لمعظم عناصر الإنتاج، وهذا من أبرز عناصر الأزمات الاقتصادية وأهم مسبباتها. ج. ضعف الموارد المتاحة للدولة لتمويل برامجها الاقتصادية وزيادة الدين العام الداخلي والخارجي والأعباء المرتبطة بهما مع زيادة عجز الموازنة العامة، ويرجع ذلك إلى أن جانبا من الأنثطة المرتبطة بغسيل الأموال عادة ما تكون أنثطة هاربة من سداد الضرائب المستحقة عليها لخزينة الدولة. (r) عطية فياض: مرجع سابق، صـ0. 
د. لجوء الحكومات إلى فرض ضرائب جديدة أو زيادة معدلات الضرائب

الحالية ومن ثم زيادة الضغط الضريبي على أفراد المجتمع وما يسببه من

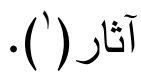

هـ ارتفاع حجم الإنفاق العام للدولة سواء لمحاربة ومكافحة الظاهرة

الإجرامية المنتشرة، أو للتغلب على الاستنزاف المستمر الذي يسببه انتشار الجريمة المنظمة في الأجهزة المختلفة، وهو ما قد يدفع الحكومة للاستدانة.

و. زيادة الفجوة بين الدخل القومي الرسمي والدخل القومي الحقيقي، مما

يصعب من مهمة السلطات في وضع خطط وبرامج فعالة للتنمية الاقتصادية بسبب العلاقة الموجودة بين الاقتصاد الخفي وعمليات غسيل الأموال. r. أثر عمليات غسيل الأموال على معدلات التضخم:

يعتبر التضخم من أهم المشاكل الاقتصادية التي تواجه معظم دول العالم، وبصفة خاصة الدول النامية، ويعرف بأنه الزيادات المتتالية في المستوى العام للأسعار والذي لا تقابله أي زيادة في العمالة والناتج القومي، ويكون تأثير

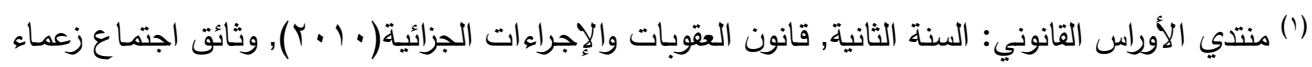

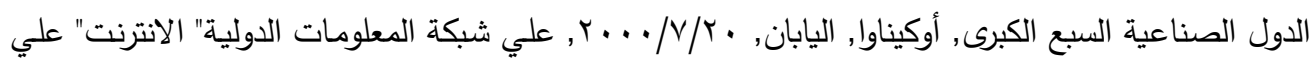
- http://sciencesjuridiques.ahlamontada.net/montada 8f. 
عمليات غسيل الأموال بالتسبب في زيادة السيولة المحلية بشكل لا يتناسب مع الزيادة في إنتاج السلع والخدمات، الأمر الذي يساهم في حدوث ضغوط تضخمية، وتدهور القوة الشرائية للنقود في الدولة التي يتم فيها غسيل الأموال، فعمليات غسيل الأموال سواء تمت في صورة نقدية عبر المصارف والتنوات المصرفية، أو في صورة عينية عن طريق شراء الذهب والعقارات و...الخ، تؤدي إلى رفع معدل التضخم بسبب زيادة المعروض من التدفقات النقدية التي تجد طريقها إلى الإنفاق الاستهلاكي من غاسلي الأموال، وهي فئات تمتاز بعدم الرشد والعشوائية في الإنفاق، مما يؤدي إلى زيادة الطلب الكلي في المجتمع ومن ثمة تدهور القيمة الثرائية للنقود(') بالإضافة إلى ذلك فعمليات غسيل الأموال تساعد على تصدير التضخم من الدول المتقدمة إلى الدول النامية بسبب دخول أموال ضخمة إلى الدول المتقدمة دون أن يقابلها زيادة في العرض السلعي مما يؤدي إلى حدوث تضخم في الدول المتقدمة، وبما أن الدول النامية تعتمد على الدول المتقدمة في حوالي •^٪ من

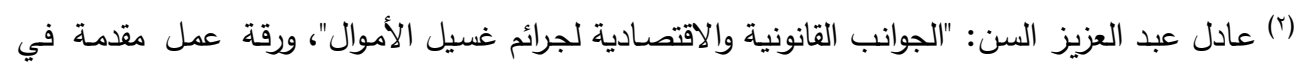

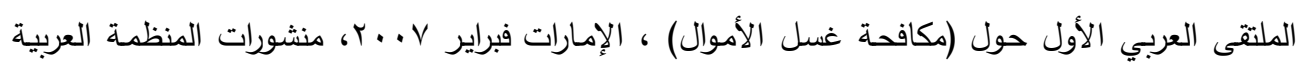

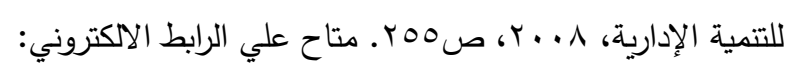
- https://www.arado.org/PublicationDetails.aspx?PubID=3832 
حجم تجارتها الدولية، فإن ارتفاع الأسعار في الدول المتقدمة يعني زيادة أسعار السلع التي تستوردها الدول النامية وهو ما يسمى "بالتضخم المستورد". r. أثر عمليات غسيل الأموال على توزيع الدخل القومي:

تؤثر عمليات غسيل الأموال سلبا على توزيع الدخل القومي، لأن مصدر هذه الأموال غير شرعي، وهذا يعني حصول فئة من المجتمع على دخل دون وجه حق، وهذا الدخل قد تم انتزاعه من الفئات المنتجة في المجتمع، وعلى هذا يحدث تحول للاخل من الفئات المنتجة التي تحصل على دخول مشروعة إلى فئات غير منتجة والتي تحصل على دخول غير مشروعة، وأكثر الأموال التي يتم غسلها ترتبط بالتهرب الضريبي، وهو ما يعني أن مكتسبي هذه الأموال سيظلون بمنأى عن سداد حقوق خزينة الدولة والتي يعتمد عليها في تمويل الخدمات الاجتماعية خاصة للطبقات الفقيرة، أي أن عمليات غسيل الأموال تحد من قدرة الدولة على إعادة توزيع الدخل بثكل أكثر عدالة (1). (') وسيم حسام الدين الأحمد: مرجع سابق, ص . . . 


\section{ع ـ أثر عمليات غسيل الأموال على الادخار المحلي:}

توجد هناك علاقة عكسية بين عمليات غسيل الأموال والادخار المحلي،

فكلما زادت عمليات غسيل الأموال قل معدل الادخار المحلي، وذلك بسبب هروب رؤوس الأموال إلى الخارج، وبالتالي ينتج عنها تناقص المدخرات التي يمكن توجيها إلى الاستثمارات، وتعجز الحكومات بذلك عن تمويل برامجها الاستثمارية ويقل التشغيل وبالتالي معدل النمو الاقتصادي وزيادة الأعباء والضغوط الاقتصادية والسياسية على البلد (').

\section{هـ أثر عمليات غسيل الأموال على معدل البطالة:}

لا يمكن الفصل بين عمليات غسيل الأموال ومعدلات البطالة سواء في

الدول المتقدمة أو في الدول النامية، حيث أن هروب الأموال عبر القنوات المصرفية أو توجيهها نحو الاكتناز في صورة مقتتيات عينية، يعني تعطيل جزء من الدخل القومي عن الاتجاه للاستثمارات اللازمة لتوفير فرص عمل للمواطنين حتى يمكن تخفيض نسب البطالة، كما أن جانبا هاما من الأموال التي يتم غسلها في الخارج إنما هي دخول ناتجة عن الفساد السياسي والذي يؤدي إلى تسرب

$$
\text { (') (1) عطية فياض: مرجع سابق، ص0V. }
$$


جزء كبير من المنح والمعونات والقروض الأجنبية إلى جيوب المفسين بدلا من أن توجه إلى الاستثمار المنتج الذي يساعد على زيادة التوظيف وتخفيض معدلات البطالة.

كما أن البطالة عادة ما تؤدي إلي دفع ضعاف النفوس للتورط في الجرائم المختلفة مثل السرقة والنصب والاحتيال والاغتصاب وإدارة بيوت الدعارة والقمار وتزوير النقود وغيرها, وهو ما يزعزع أمن واستقرار المجتمعات(').

\section{4. أثر عمليات غسيل الأموال على نمط الاستهلاك:}

تتسم التصرفات الاستهلاكية وأنماط الإنفاق في حالة الحصول على أموال غير مشروعة غير ناتجة عن جها إنتاجي حقيقي، تتصف بالسفه والتبذير، كالإنفاق على الدخدرات والدعارة والقمار وغيرها من المجالات غير المشروعة، مما يعني انتشار الاستهلاك المظهري(ب) وزيادة معدلات تبديد الموارد المتاحة لدوافع نفسية أو اجتماعية، فعادة يتجه أصحاب هذه الدخول إلى تعويض الحرمان من الترف خلال سنوات المعاناة والتي سبقت الحصول على الأموال غير المشروعة، حيث يتجهون إلى الإنفاق على شراء الذهب والتحف الفنية

$$
\begin{aligned}
& \text { (r) وسيم حسام الدين الأحمد: مرجع سابق, ص بر. (r). }
\end{aligned}
$$

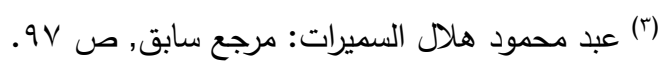


واستهلاك السلع المستوردة من الخارج بأسعار خيالية، ولهذا تصبح هذه الثقافة الاستهلاكية قيمة في حد ذاتها لدى أصحاب الدخول غير المشروعة('). V. أثر عمليات غسيل الأموال على السياسات الاقتصادية: تؤثر عمليات غسيل الأموال علي استقرار الاقتصادي الكلي, وكذلك على صياغة السياسات الاقتصادية سواء المالية أو النقدية أو التجارية، وذلك لعدم دقة البيانات والمعلومات اللازمة لصياغة هذه السياسات، ومن ثمة تحد من كفاءتها وفاعليتها في تحقيق الاستقرار الاقتصادي، فنظرا لاعتماد تخطيط وإدارة السياسات الاقتصادية في الدولة على السيولة المتوفرة لدى المصارف، ولما كانت الأموال المراد غسلها تتنقل من دولة لأخرى بمبالغ كبيرة وبشكل مفاجئ، الأمر الذي يؤدي إلى انخفاض مقدار السيولة في الدولة المحول منها الأموال لتزيد من السيولة فجأة في الدولة المحول إليها الأموال المغسولة، فيؤدي هذا التحول المفاجئ إلى خلل في المخطط الاقتصـادي للدولة المحول منها، كما يخلق في (1) سعيد سعيد ناصر الحمدان وسيد جاب الله السيد: "المصاحبات الاقتصادية والاجتماعية لجريمة غسيل

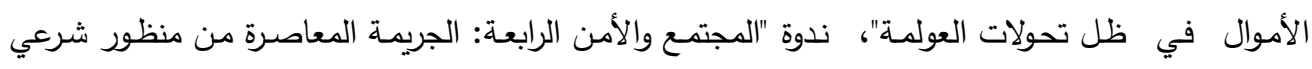

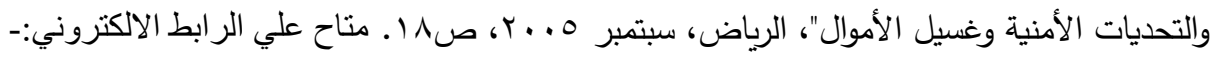
https://www.kfsc.edu.sa/ResearchCenter/ExhibitionsSeminars/Seminars/PreviousS eminars/Fourth/Pages/fou3.aspx. 
الدول المحول إليها اعتقادا خاطئا بأن هناك وفرة في السيولة بسبب التوسع الاقتصادي المصاحب لدخول الأموال المراد غسلها، مما يدفع السلطات النقدية إلى إتباع سياسة نقدية وائتمانية تقوم على الحد من التوسع الاقتصادي، ثم تفاجأ بالتحركات العكسية لهذه الأموال وتحولها مرة أخرى إلى الخارج، وهنا تكتثف أنها اتبعت سياسات اقتصادية خاطئة لا تعبر عن حاجة الاقتصاد الفعلية ('). وبشكل عام فقد أشـارت دراسـة كل من "جون ماكدويل"، "غاري نوفيس", بمكتب شؤون المخدرات الدولية وإنفاذ القانون، بوزارة الخارجية الأمريكية, بعنوان "عواقب غسل الأموال والجريمة المالية", إلي أن الآثار الاقتصادية لغسيل الأموال

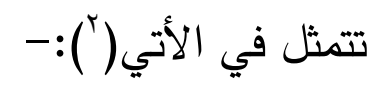
| - 1 - تقويض مشروعات القطاع الخاص. r- (- تقويض نزاهة الأسواق المالية. r- فقدان السيطرة على السياسة الاقتصادية.

${ }^{(2)}$ Brent L. Bartlett; Economic Research Report: The Negative Effects of Money Laundering on Economic Development, The Asian Development Bank Regional Technical Assistance Project No.5967 Countering Money Laundering in The Asian and Pacific Region, May 2002,p.p. 23 -24.

(1) John McDowell, And Gary Novis; THE CONSEQUENCES OF MONEY LAUNDERING AND FINANCIAL CRIME, Economic Perspectives An Electronic Journal of the U.S. Department of State, Vol. 6, No. 2, May 2001,p.p. 7-8. 


$$
\begin{aligned}
& \text { ؟- التشويه وعدم الاستقرار الاقتصادي. } \\
& \text { 0- خسارة الإيرادات الحكومية. } \\
& \text { צ- ضياع جهود الخصخصة. } \\
& \text { - V تأثر سمعة المؤسسات المالية. }
\end{aligned}
$$

ومن هنـا تصـنف ظـاهرة غسيل الأموال علي أنها جريمـة اقتصـادية بالمقام

الأول لأن نشـاطها ينصـب علي محاور الاقتصـاد مـن إنتاج وتدوير واستهلاك فيؤثر ويتأثر بها, وأن هذه الجريمـة تنتهك هدفين أساسيين في القانون الجنائي الاقتصادي وهما: حماية المنافع والفوائد وإدارة اقتصـاد الدولة. ولا شك أن السعي نحو تحقيق تلك الانتهاكات يفرض طابعاً تقنياً لارتكاب الجريمة('). ولا يقتصر التأثير السلبي لعمليات غسيل الأموال على النواحي الاقتصادية والاجتماعية في المجتمع فقط، وإنما يتعداه ليشمل أيضا النواحي السياسية والأمنية، ومن أهم هذه الآثار نجد(؟):

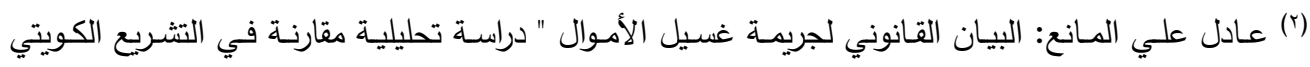

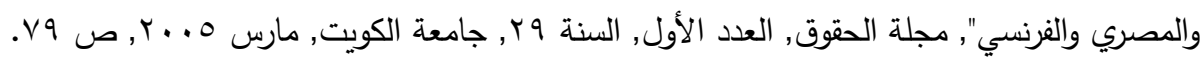

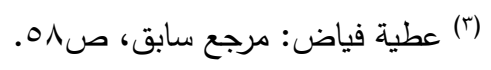


أ. زعزعة الاستقرار السياسي والاجتماعي وحدوث الانقلابات السياسية في

كثير من البلدان النامية، وذلك لاستخدام عمليات غسيل الأموال في توفير

الدعم المالي وشراء السلاح اللازم لحدوث الانقلابات وإمداد جميع الأطراف

المتصارعة بما يلزمها من مال وعتاد مقابل الحصول على ثروات هذه

البلدان.

ب. وجود علاقة وثيقة بين عمليات غسيل الأموال ونشاط الجاسوسية السياسية

حيث تحتاج أجهزة المخابرات والجاسوسية إلى التمويل اللازم لعملياتها

السرية حول العالم، ومن ثم تتجه إلى استخدام القنوات المصرفية في العديد

من الدول في توجيه الأموال من دول التجميع إلى دول مزاولة العمليات الجاسوسية في مختلف دول العالم.

ج. توجيه الأموال المغسولة إلى تمويل المنظمات الإجرامية والجماعات الإرهابية، ودعم النزاعات العرقية والدينية من أجل القيام بعملياتهم وجرائمهم التخريبية مما يؤدي إلى زعزعة الأمن والاستقرار في الدولة من جهة، واستخدام الإعلام لقلب الحقائق من جهة أخرى. 
د. تؤدي العمليات المشبوهة إلى تسرب أصحاب رؤوس الأموال غير المشروعة للتمثيل في المجالس الثعبية والنيابية، الأمر الذي يفضي إلى تمتع هؤلاء بالحصانة والاشتراك في وضع تشريعات الدولة، وذلك بفضل ما لديهم من إمكانات في الإنفاق على الحملات الانتخابية، وشراء الذمم والتأثير على أصوات الناخبين، وقد تمتد نشاطاتهم إلى جميع الأنشطة الثقافية والرياضية في الدولة، مما يفضي في النهاية إلى الفوضى وفساد

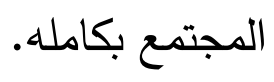

هـ تمكن عمليات غسيل الأموال جماعات الإجرام المنظم من إفساد الموظفين وخاصة رجال القانون وتطبيقه وغيرهم عن طريق الرشوة، وذلك ليأمنوا عدم

$$
\text { ملاحقتهم جنائيا ويعيشون في حالة مهادنة معهم (') }
$$

يري الباحث من خلال ما تقدم أن ظاهرة غسيل الأموال أصبحت من أهم الأنشطة الاقتصادية الإجرامية التي تحقق عوائد عالية، فالهدف الرئيسي لهذه الظاهرة هو إخفاء مصدر الأموال المكتسبة من نشاطات غير شرعية وتحويلها 
عن طريق الكثير من الأساليب، سواء كانت تقليدية أو حديثة، إلى أموال مشروعة لا تثير الثبهات ولا يمكن متابعتها.

ورغم أن ظاهرة غسيل الأموال ليست وليدة هذا القرن، إلا أن بداياتها الفعلية

كانت في ثمانينيات القرن الماضي، وذلك نتيجة للكثير من الأسباب، كعدم وجود العقوبات الرادعة وارتفاع معدلات الفقر والبطالة في المجتمعات، وكذا بسبب بحث الغاسلين عن الأمان واكتساب صفة شرعية لأموالهم غير المشروعة، والتي تعد أنشطة تجارة المخدرات والسلاح والجريمة المنظمة وعمليات السرقة والغصب والاختلاس وتجارة البشر من أهم مصادرها.

وفيما يخص حجم هذه الظاهرة، أشارت مختلف الاجتهادات والتوقعات في هذا الخصوص إلى أن حجمها يتزايد من سنة لأخرى، وقد وصل الرقم إلى مئات المليارات من الدولارات، وهو مرشح للزرتفاع بسبب استمرار هذه الظاهرة واتساعها وارتباطها بعلاقة وثيقة بنشاطات أكثر خطورة كالاقتصاد الخفي والفساد والإرهاب.

نتائج البحث:

حاول الباحث من خلال البحث أن يتوصل إلي النتائج التالية: 
1- أن جريمة غسيل الأموال لا تقف عند حد امتلاك شخص لمال غير مشروع وإدخاله في النظام المالي للدولة، بل في الحقيقة تتعدد أنماطها وتطال المسؤولية مرتكبيها والمساهمين فيها والمتداخلين والمنتفعين. r- تصنف ظاهرة غسيل الأموال علي أنها جريمة اقتصادية بالمقام الأول لأن نشاطها ينصب علي محاور الاقتصاد من إنتاج وتدوير واستهلاك فيؤثر ويتأثر بها. r- أن أسباب عمليات غسيل الأموال. قد تكون مباشرة مثل البحث عن الأمان واكتساب الثرعية خشية المطاردة القانونية, أو وجود بعض الدول التي تثجع عمليات غسيل الأموال, أو لعدم وجود العقوبات الرادعة. وأن الأسباب غير المباشرة تتمثل في الفقر والبطالة, وارتفاع معدلات الضرائب والرسوم والفساد الإداري والسياسي في بعض الدول. ـ - يوجد تأثير سلبي لعمليات غسيل الأموال على النواحي الاقتصادية, حيث تتؤثر سلبا على الدخل القومي وتوزيعه, وارتفاع معدلات البطالة والتضخم, كما تؤثر عمليات غسيل الأموال علي استقرار الاقتصادي الكلي, وكذلك على صياغة السياسات الاقتصادية سواء المالية أو النقدية أو التجارية للدول المتأثرة بتلك الظاهرة السلبية. 


\section{التوصيات:}

1- العمل علي مكافحة أسباب عمليات غسيل الأموال دولياً ومحلياً. r- التعاون الدولي وتبادل المعلومات لوضع آليات عملية للحد من هذه الظاهرة.

r-عقدـ مـؤتمرات دوليـة وإقليميـة عـن غسـيل الأمسوال, ونثـر توصـياتها للاستفادة منها.

\section{مراجع البحث: \\ أولاً: المراجع العربية: - العيجية}

1- أحمد صبحي جميل ، الآثار الاقتصادية والاجتماعية لظاهرة غسيل الاموال

ودور المصارف في مكافتها (دراسة استطلاعية في عينة من المصارف العراقية

) ، مجلة كلية بغداد للعلوم الاقتصـادية ، الكلية التقنية الإداريـة ، العدد السـابع والعشرون ، 11. 1 . .

r- قانون رقمه ب لسنة +..rفي شأن مكافحة عمليات غسيل الأموال: دولة الكويت. 
r- حامد عبد اللطيف عبد الرحمن، "جريمة غسل الأموال وسبل مكافحتها"، رسـالة ماجستير في العلوم الجنائية والثـرطية من كلية تدريب الضـباط ، الأكاديمية الملكية للشرطة، وزارة الداخليــــة، مملكة البحرين، با ـ Y. ع - اتفاقية الأمم المتحدة لمكافحة الاتجار غير المشروع في المخدرات والمؤثرات

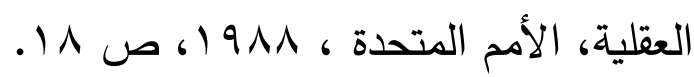
0- اتفاقية الأمم المتحدة لمكافحة الجريمة المنظمة عبر الوطنية والبروتوكولات الملحقـة بهـا، المكتب المعنـي بالمخدرات والجريمـة، الأمـم المتحدة، نيويـرك،

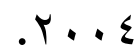
צ- أديب ميالة ومي محرزي، الإطار التشريعي لجريمة غسل الأموال في سورية، مجلة جامعة دمثق للعلوم الاقتصادية والقانونية، المجلد ـ، العدد الثاني،

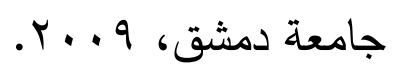

V- تمـيم طـاهر أحمد، المسؤولية الجنائيـة عن جـرائم غسيل الأمـوال، مجلــة الحقوق، كليـة القـانون، الجامعـة المستنصـرية، بغداد، المجلد الخـامس، العدد

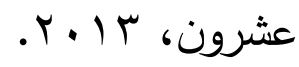

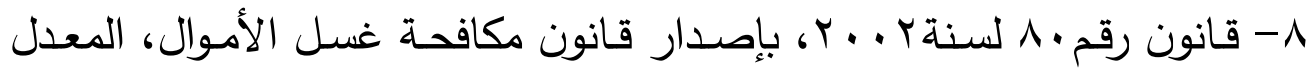

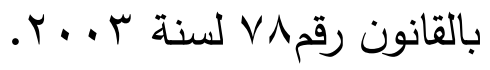


9-عـادل علي المـانع: البيان القـانوني لجريمـة غسيل الأمسوال " دراسـة تحليليـة مقارنـة في التشـريع الكـويتي والمصـري والفرنسي", مجلـة الحقوق, العدد الأول,

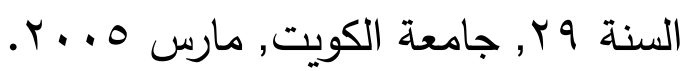
• 1- السيد عبد الوهاب عرفة، "الثـامل في جريمة غسل الأموال, المكتب الفني اللموسوعات القانونية" ، الإسكندرية، 9 . . . . 1ا - الأخضر عزي، " دراسة ظاهرة تبييض الأموال عبر البنوك (تحليل الظاهرة في البنوك الجزائريـة) ، مجلة الحقوق والعلوم الإنسـانية، مجلة دوليـة دوريـة محكمـة، العـدد الاقتصـادي السـادس والعشـرون، المجلد الأول، جامعـة زيـان عاشور بالجلفة، الجزائر ، مارس 7 ا ـ Y. r ا السيسي صـلاح الدين حسن ، غسيل الأموال "الجريمـة التي تهدد استقرار الاقتصاد الدولي" ، دار الفكر العربي، القاهرة ، ب . . . . با - الطيف عائشـة، "ظاهرة غسيل الأموال وأثرها علي اقتصساديات دول العالم العربـي دراسـة حالـة الجزائر "، كليـة العلـوم الاقتصـادية وعلـوم التسييير ، جامعـة

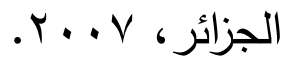


ع ا- محمد بن احمد صـالح الصـالح، "غسل الأموال في النظم الوضعية رؤيـة إسلامية" ، المؤتمر العالمي الثالث للاقتصـاد الإسـلامي، جامعة أم القرى، مكة المكرمة، بدون تاريخ. 10- نصــيرة حساجي، " الإطــار القــانوني لجريــة تبـيض الأمـوال "، رسـالة ماجستير ، كلية الحقوق والعلوم السياسية، جامعة العربي بن مهيدي بأم البواقي،

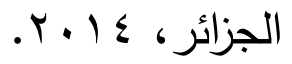

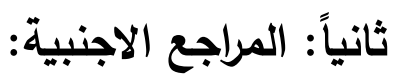

${ }^{(1)}$ Brent L. Bartlett; Economic Research Report: The Negative Effects of Money Laundering on Economic Development, The Asian Development Bank Regional Technical Assistance Project No.5967 Countering Money Laundering in The Asian and Pacific Region, May 2002.

(2) Hasmet Sarigul; MONEY LAUNDERING AND ABUSE OF THE FINANCIAL SYSTEM, International Journal of Business and Management Studies, 2013. 
(3) John McDowell, And Gary Novis; THE CONSEQUENCES OF MONEY LAUNDERING AND FINANCIAL CRIME, Economic Perspectives An Electronic Journal of the U.S. Department of State, Vol. 6, No. 2, May 2001.

(4) Pasley, Robert, S (Editor).; "Study Guide for the CAMS Certification Examination", Fifth Edition, the Association of Certified Anti-Money Laundering Specialists (ACAMS), Miami, USA, 2002.

(5) Nikos Passas; Financial intermediaries - Anti-money laundering allies in cash-based societies?, AntiCorruption Resource Centre, U4 Issue, April 2015.

${ }^{(6)}$ World Bank Institute (2002) Christian Eigen-Zucchi with the assistance of Erin Farnand under the guidance of Daniel Kaufmann Anti-Money Laundering Literature Search AlphabeticalWorldBank 
Institute(http://www.worldbank.org/wbi/governance) visited on: $1 / 3 / 2020,2.00 a m$.

ثالثاً: مقالات علي شبكة المعلومات الدولية: ا- عـادل عبـد العزيـز السـن: "الجوانـب القانونيــة والاقتصـادية لجـرائم غسيل الأموال"، ورقة عمل مقدمة في الملتقى العربي الأول حول (مكافحة غسل الأموال) ، الإمارات فبراير V . . Y، منشورات المنظمة العربية للتنمية الإدارية،

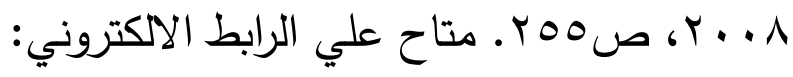

https://www.arado.org/PublicationDetails.aspx?PubID=3832

r- سعيد سعيد ناصر الحمدان وسيد جاب الله السيد: "المصساحبات الاقتصادية والاجتماعية لجريمة غسيل الأموال في ظل تحولات العولمـة"، ندوة "المجتمع والأمن الرابعة: الجريمة المعاصرة من منظور شرعي والتحديات الأمنية وغسيل الأموال"، الرياض، سبتمبر 0 . . ب، ص^^ ا ـ متاح علي الرابط الالكتروني:https://www.kfsc.edu.sa/ResearchCenter/ExhibitionsSeminar s/Seminars/PreviousSeminars/Fourth/Pages/fou3.aspx. 
ب- اللجنـــة الدوليـــة لمكافحـــة عمليــات غســل الأمـــوال حـــول العــالم

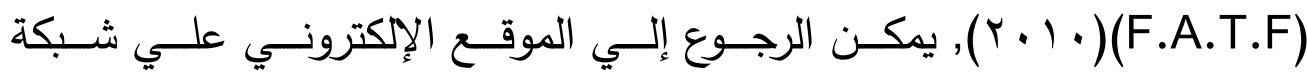

المعلومات الدولية" الانترنت",علي الرابط:

.(WWW.Fatf-gafi.com )

ع- منتــدي الأوراس القـانوني: الســنة الثانيــة, قـانون العقوبـات والإجــراءات

الجزائية ( • • ب), وثائق اجتماع زعماء الدول الصناعية السبع الكبرى, أوكيناوا,

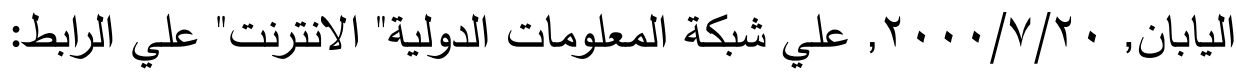

- http://sciencesjuridiques.ahlamontada.net/montada 8f. 